\section{Commentary: How to train residents... and how to train attendings to train residents: One train can hide another}

\author{
David Kalfa, MD, PhD, and Emile Bacha, MD
}

In this issue of the Journal, the group led by Vaughn Starnes examines how the education of congenital heart surgery residents influences the surgical outcomes of the group. ${ }^{1}$ Over a 10-year period, 3406 American Board of Thoracic Surgery index cases were categorized into 2 groups according to primary surgeon: attending and resident. The authors performed a multivariable logistic regression analysis examining the effect of operating surgeon on short-term outcomes before and after a propensity score matching designed to balance differences between the 2 cohorts.

Their results are compelling. Their prematching analysis showed that trainee patients do not have worse outcomes compared to attending patients. The logistic regression modeling after matching demonstrated equivalent 30-day mortality, 30-day major morbidity, and length of stay. The study also describes precisely the amount and types of cases performed by residents in this highly recognized training program.

Despite minor limitations related to the retrospective examination of only short-term outcomes and the possible presence of selection bias not controlled by the propensity matching, the authors reasonably conclude from their data that there is no difference in short-term outcomes when comparing similar cases operated by attendings versus residents in their institution.

\footnotetext{
From the Section of Pediatric and Congenital Cardiac Surgery, Division of Cardiac, Thoracic, and Vascular Surgery, Columbia University Medical Center, New York Presbyterian-Morgan Stanley Children's Hospital, New York, NY.

Disclosures: The authors reported no conflicts of interest.

The Journal policy requires editors and reviewers to disclose conflicts of interest and to decline handling or reviewing manuscripts for which they may have a conflict of interest. The editors and reviewers of this article have no conflicts of interest.

Received for publication Jan 25, 2021; revisions received Jan 25, 2021; accepted for publication Jan 26, 2021; available ahead of print Feb 4, 2021.

Address for reprints: David Kalfa, MD, PhD, Pediatric Cardiac Surgery, Columbia University Medical Center, New York Presbyterian-Morgan Stanley Children's Hospital, 3959 Broadway, New York, NY 10032 (E-mail: dk2757@cumc. columbia.edu).

J Thorac Cardiovasc Surg 2022;163:261-2

$0022-5223 / \$ 36.00$

Copyright (c) 2021 by The American Association for Thoracic Surgery

https://doi.org/10.1016/j.jtcvs.2021.01.117
}

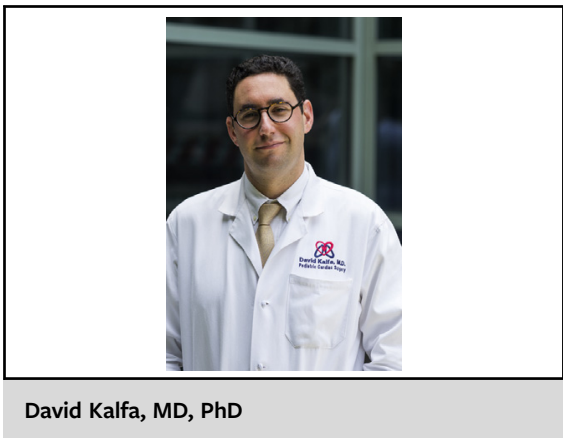

CENTRAL MESSAGE

Case selection, graded responsi-

bility, and faculty commitment are keys to resident education. Training the new generation of educators is key as well.

This remarkable study is a landmark publication as it is the first study that examined in a systematic way the impact of training on results in congenital heart surgery. In the era of transparency and public outcomes reporting, ensuring the absence of a negative impact of resident education on patient outcomes is key. We know the ingredients for the recipe for an outstanding education program: case selection, graded responsibility, and commitment of the faculty to education are all necessary elements. But they are not sufficient. Indeed, the reproducibility of the recipe can be undermined because of a consultant-driven referral pattern, financial pressures, or the lack of support systems in an institution. The second attending surgeon scrubbing as a second assistant in all cases in Starnes group might not be reproducible in many centers in and outside of the United States. A second year of fellowship would tremendously help many US training centers by offering residents a training extension period in a center that knows them and that they know and where they can keep developing their operating skills on the most complex cases in a "noncompetitive" environment given their official trainee position. A 2-year (or longer) fellowship is already the rule in many European countries.

The next step for our specialty is probably to systematize the way to train young attendings to train residents. Education itself should be included in the training program. And after joining a group, a new attending should be ideally put in an environment with low pressure, low competition, and an established referral pattern where the young attending can be trained and mentored on how to train. A sustainable 
training program should be based not only on the heritage of past great surgical educators, but also on training the new generation of surgeons (-scientists)-teachers. New locomotives are needed for the moving train.

\section{Reference}

1. Cleveland JD, Bowdish ME, Mack WJ, Kim RW, Kumar SR, Kallin K, et al. Resident education in congenital heart surgery does not compromise outcomes. $J$ Thorac Cardiovasc Surg. 2022;163:251-60.
See Article page 251.

\section{Commentary: Resident education in congenital heart surgery: Is this the best we can do?}

James Jaggers, MD, and Emily A. Downs, MD
"Now this is not the end. It is not even the beginning of the end. But it is, perhaps, the end of the beginning." -Winston Churchill

The responsibilities of a surgical educator are many: responsibility to their patients, learners, colleagues, and community. This study by Cleveland and colleagues ${ }^{1}$ reports their 10-year experience in educating congenital cardiac surgical residents in which surgical mortality was no different between resident or attending primary surgeon. They go on to report that all their residents met their case requirements and have confirmed that 8 of 9 residents who pursued congenital cardiac surgery careers are board certified and actively practicing. This represents an excellent achievement, and we all recognize these authors as master educators and outstanding surgeons with a high-quality program. The study validates our own educational history, bolsters our ideals of traditional surgical education, but likely reinforces our own cognitive biases.

Is the strategy described in this report the best we can do? One year of graduated surgical experience culminating in

From the University of Colorado and Children's Hospital Colorado, Aurora, Colo. Disclosures: The authors reported no conflicts of interest.

The Journal policy requires editors and reviewers to disclose conflicts of interest and to decline handling or reviewing manuscripts for which they may have a conflict of interest. The editors and reviewers of this article have no conflicts of interest.

Received for publication Jan 4, 2021; revisions received Jan 4, 2021; accepted for publication Jan 5, 2021; available ahead of print Jan 13, 2021.

Address for reprints: James Jaggers, MD, Children's Hospital Colorado, 13123 East 16th Ave, Aurora, CO 80045 (E-mail: James.Jaggers@ childrenscolorado.org).

J Thorac Cardiovasc Surg 2022;163:262-3

$0022-5223 / \$ 36.00$

Copyright (c) 2021 by The American Association for Thoracic Surgery

https://doi.org/10.1016/j.jtcvs.2021.01.010
Check for updates

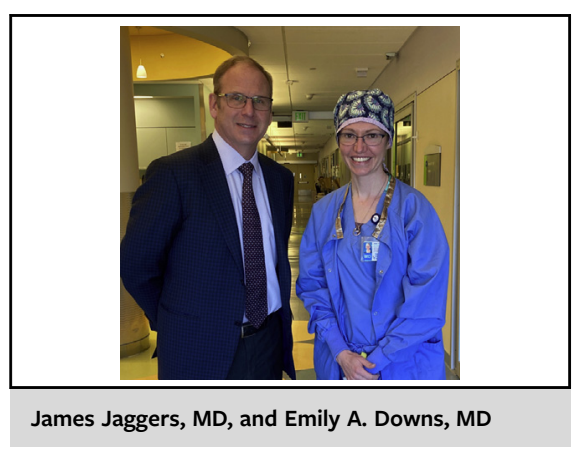

CENTRAL MESSAGE

Congenital cardiac surgery

training is a lifelong endeavor.

Fellowship is the end of the

beginning. More years of training

may not result in better educa-

tion or better surgeons.

"adequate" total cases, with an average of 5.4 complex procedures over the year of training. Is this enough to instill the confidence for the resident to practice independently? Of course not, nor has it ever been. Completion of residency is just the beginning.

Despite the authors' success highlighted in this current report, they, like others, are changing to a 2-year program. Do we really believe that the extra year will translate into readiness for independent practice? I have doubts. Significant improvements in our training program may require implementing new innovations in education. Work smarter, not harder (or longer). Simulation for example, has been shown to be effective in preparing the learner in specific technical skills necessary to accomplish complex repairs in a timely manner, ${ }^{2}$ an effective strategy to triage skillbuilding early in fellowship. Surgical simulation with 3dimensional printed models of complex defects allows the resident to become familiar with the cogent anatomy and rehearse the operation before live surgery. ${ }^{3}$ It offers the potential of individualization, allowing progression or 